\title{
Butyrate stimulates tissue-type plasminogen-activator synthesis in cultured human endothelial cells
}

\author{
Teake KOOISTRA,* Jeannette VAN DEN BERG, Annemiek TÖNS, Gerard PLATENBURG, \\ Dingeman C. RIJKEN and Eva VAN DEN BERG \\ Gaubius Institute TNO, Herenstraat 5d, 2313 AD Leiden, The Netherlands
}

\begin{abstract}
Incubation of cultured human endothelial cells with 5 mM-dibutyryl cyclic AMP led to an approx. 2-fold increase in tissue-type plasminogen-activator (t-PA) production over a $24 \mathrm{~h}$ incubation period. The stimulating effect of dibutyryl cyclic AMP could be explained by the slow liberation of butyrate, as the effect could be reproduced by addition of free butyrate to the medium, but not by addition of 8-bromo cyclic AMP or forskolin, agents known to raise intracellular cyclic AMP levels. With butyrate, an accelerated accumulation of t-PA antigen in the conditioned medium (CM) was observed after a lag period of about $6 \mathrm{~h}$. Increasing amounts of butyrate caused an increasingly stimulatory effect, reaching a plateau at $5 \mathrm{mM}$ butyrate. The relative enhancement of t-PA production in the presence of $5 \mathrm{~mm}$-butyrate varied among different endothelial cell cultures from 6- to 25 -fold in $24 \mathrm{~h}$ CM. Such an increase in t-PA production was observed with both arterial and venous endothelial cells. The butyrate-induced increases in t-PA production were accompanied by increased t-PA mRNA levels. Analysis of radiolabelled CM and cell extracts by SDS/ polyacrylamide-gel electrophoresis indicated that the potent action of butyrate is probably restricted to a small number of proteins. The accumulation of plasminogen activator inhibitor type 1 (PAI-1) in CM from butyrate-treated cells varied only moderately. In our study of the relationship between structure and stimulatory activity, we found that a straight-chain $\mathrm{C}_{4}$ monocarboxylate structure with a methyl group at one end and a carboxy moiety at the other seems to be required for the optimal induction of t-PA in cultured endothelial cells.
\end{abstract}

\section{INTRODUCTION}

The plasma fibrinolytic system is primarily responsible for the degradation of fibrin, the matrix structure of blood clots. Fibrin is deposited by the coagulation system as a response to vascular injury and serves as a matrix to restore a haemostatic condition. A delicate balance between the fibrinolytic system and the coagulation system underlies the maintenance of continuous blood flow and prevents haemorrhagic as well as thrombotic phenomena. Impairment of fibrinolysis may predispose to thrombosis. A great deal of interest is involved in the search for (synthetic) agents with profibrinolytic properties to exploit the natural system of thrombolysis and to gain long-term fibrinolytic prophylaxis against degenerative vascular disorders.

Tissue-type plasminogen activator (t-PA) is considered to play an important role in the onset of the extrinsic fibrinolytic route through conversion of the zymogen plasminogen into the active enzyme plasmin which can degrade fibrin. The availability of t-PA may thus be of prime importance for the fibrinolytic capacity of plasma. The activity of t-PA in the bloodstream is regulated at various levels, e.g. by the release of t-PA into the circulation (Emeis et al., 1985). Plasma t-PA is presumed to be mainly derived from the vascular wall, where it is localized in the endothelial cell (Todd, 1959; Rijken et al., 1980). Little is known, however, about the mechanism(s) by which t-PA synthesis by the endothelium is regulated. Insight into this regulation might enable us to influence plasma t-PA levels, and thereby plasma fibrinolytic capacity.

In recent years it has become clear that circulating $t$ PA activity is further controlled by a specific, fast-acting inhibitor, directed against both tissue-type and urokinase-type plasminogen activator (Kruithof et al., 1984; Verheijen et al., 1984; Wiman et al., 1984). The origin of this so-called plasminogen activator inhibitor type 1 (PAI-1) in plasma is not known, but an inhibitor closely related with regard to $M_{\mathrm{r}}$, dissociation constant with t-PA, immunological characteristics, and instability at $37^{\circ} \mathrm{C}$ has been demonstrated in, among others, the conditioned medium (CM) of cultured endothelial cells (Sprengers, 1986; Erickson et al., 1985; Sprengers et al., 1985).

We have used cultured human endothelial cells to study the effect of various physiological and pharmacological agents on t-PA production in vitro. During this search for compounds that can enhance t-PA production, we found that dibutyryl cyclic AMP led to an increase in t-PA production by endothelial cells (Kooistra et al., 1985). In this paper, we show that the stimulating effect of dibutyryl cyclic AMP is probably due to the slow liberation of butyrate residues, as the effect can be reproduced by addition of free butyrate to the medium, but not by addition of 8-bromo cyclic AMP or forskolin. Furthermore, we describe the specificity, kinetics, structural requirements and regulatory mechanism of the butyrate-mediated stimulation of t-PA synthesis in cultured human endothelial cells. The (relative) specificity

Abbreviations used: t-PA, tissue-type plasminogen activator; PAI-1, plasminogen activator inhibitor type 1; CM, conditioned medium; poly(A) ${ }^{+}$RNA, polyadenylated RNA; SSC, $0.15 \mathrm{M}-\mathrm{NaCl} / 0.015 \mathrm{M}$-sodium citrate.

* To whom correspondence should be addressed. 
of butyrate towards t-PA synthesis is illustrated by the absence of a comparable effect on the production of PAI-1.

\section{MATERIALS AND METHODS}

\section{Materials}

A crude preparation of endothelial-cell growth factor was prepared from bovine hypothalamus as described by Maciag et al. (1979). Culture reagents were purchased from Flow Laboratories, Irvine, Ayrshire, Scotland, U.K., and plastics were obtained from Costar, Cambridge, MA, U.S.A. Sterile, pyrogen-free, human serum albumin was from the Centraal Laboratorium van de Bloedtransfusiedienst, Amsterdam, The Netherlands. $\left[{ }^{35} \mathrm{~S}\right]$ Methionine $(1084 \mathrm{Ci} / \mathrm{mmol})$ and $\mathrm{En}^{3} \mathrm{Hance}$ (autoradiofluorography enhancer) were supplied by New England Nuclear Corp., Boston, MA, U.S.A. t-PA ( $>99 \%$ two-chain) was purified from Bowes-melanomacell culture medium as described by Kluft et al. (1983). The activity is expressed as international units (i.u.), using the first international standard of the World Health Organization, code $83 / 517$, as a standard (Gaffney \& Curtis, 1985). One i.u. of PAI-1 activity is defined as the quantity of inhibitor that neutralizes $1 \mathrm{i}$.u. of t-PA. The reagents used in SDS/polyacrylamide-gel electrophoresis, fibrin-autography and PAI-1 assay have been described in detail elsewhere (Sprengers et al., 1984). An e.l.i.s.a. kit for t-PA antigen determination was purchased from Biopool (Umea, Sweden). Protein $M_{\mathrm{r}}$ standards for SDS/polyacrylamide-gel electrophoresis were from Bio-Rad, Richmond, CA, U.S.A. Dibutyryl cyclic AMP, 8-bromo cyclic AMP, forskolin, sodium acetate, propionic acid sodium salt, n-butyric acid sodium salt, valeric acid, $\mathrm{n}$-hexanoic acid sodium salt, isobutyric acid, crotonic acid, butanol, $\gamma$-butyrolactone, 2-hydroxybutyric acid sodium salt, 3-hydroxybutyric acid sodium salt, 4-hydroxybutyric acid sodium salt, 2-oxobutyric acid sodium salt, 4-amino- $N$-butyric acid (GABA), succinic acid disodium salt, and butyric acid ethyl ester were purchased from Sigma. Methoxyacetic acid was from Aldrich. Free acids of butyrate analogues were neutralized with stoichiometric amounts of $\mathrm{NaOH}$ to prepare the corresponding sodium salts. Solutions for cell culture were sterilized by filtration through $0.2 \mu \mathrm{M}$-Gelman Acrodisc filters. All other reagents were of the highest grade available.

\section{Cell culture}

Endothelial cells from human umbilical veins or arteries were isolated by the method of Jaffe et al. (1973), and cultured as previously described (Van Hinsbergh et al., 1983). Cells were grown on fibronectin-coated flasks in M199 medium, supplemented with $20 \mathrm{mM}$-Hepes, $20 \%(\mathrm{v} / \mathrm{v})$ human serum (heat-inactivated), $200 \mu \mathrm{g}$ of endothelial cell growth factor preparation $/ \mathrm{ml}, 100$ i.u. of penicillin $/ \mathrm{ml}$, and $100 \mu \mathrm{g}$ of streptomycin $/ \mathrm{ml}$ under a $\mathrm{CO}_{2}$ atmosphere. Subcultures were obtained by trypsin/ EDTA treatment at a split ratio of $1: 3$.

\section{Conditioned media (CM) and cell lysates}

Confluent cultures were used at second or third passage, and were always re-fed the day before the experiment. CM were obtained by incubating $5 \mathrm{~cm}^{2}$ of cells at $37^{\circ} \mathrm{C}$ for various times up to $24 \mathrm{~h}$ with $1 \mathrm{ml}$ of medium supplemented with $10 \%(\mathrm{v} / \mathrm{v})$ human serum, penicillin and streptomycin and the appropriate concentration of the test compound (incubation medium). CM were centrifuged for 2 min in a Beckman Microfuge to remove cells and cellular debris, and samples were frozen at $-20^{\circ} \mathrm{C}$ until use. Cell lysates were prepared by washing the cells twice with ice-cold phosphate-buffered saline $(0.14 \mathrm{M}-\mathrm{NaCl} / 0.01 \mathrm{M}$-sodium phosphate, $\mathrm{pH} 7.2)$ followed by scraping the cells off the dish with a rubber policeman in the presence of ice-cold phosphate-buffered saline, containing $0.5 \%(\mathrm{w} / \mathrm{v})$ Triton X-100. Cell lysates were also frozen at $-20^{\circ} \mathrm{C}$ until use.

\section{Overall protein synthesis}

Overall protein synthesis was determined by measuring the incorporation of $\left[{ }^{35}\right.$ S]methionine into the $10 \%(\mathrm{w} / \mathrm{v})$ trichloroacetic acid-precipitable fraction of radiolabelled CM and cell extract. To that end, endothelial cells were incubated with incubation medium and $5 \mu \mathrm{Ci}$ of $\left[{ }^{35} \mathrm{~S}\right]-$ methionine $/ \mathrm{ml}$. Radiolabelled CM and cell lysates were collected as described above for unlabelled samples. $100 \mu \mathrm{l}$ of a $20 \%$ (w/v) trichloroacetic acid solution was added to $100 \mu \mathrm{l}$ portions of $\mathrm{CM}$ or cell extract. After $16 \mathrm{~h}$ at $4{ }^{\circ} \mathrm{C}$, the precipitate was centrifuged and washed twice with $1 \mathrm{ml}$ of ice-cold $5 \%(\mathrm{w} / \mathrm{v})$ trichloroacetic acid solution. The final pellet was dissolved in $0.3 \mathrm{ml}$ of $0.3 \mathrm{M}-$ $\mathrm{NaOH}$, and, after addition of $60 \mu \mathrm{l}$ of $1.5 \mathrm{M}-\mathrm{HCl}$ and $10 \mathrm{ml}$ of Picofluor, it was counted in a Packard TriCarb liquid scintillation counter.

\section{Radiolabelling of endothelial-cell proteins}

Incorporation of $\left[{ }^{35} \mathrm{~S}\right]$ methionine into endothelial-cell proteins took place during a $2 \mathrm{~h}$ incubation of endothelial cells with M199 medium (methionine-free), supplemented with $0.03 \%(w / v)$ human serum albumin, Hepes, penicillin and streptomycin as described above, and $20 \mu \mathrm{Ci}$ of $\left[{ }^{35} \mathrm{~S}\right]$ methionine $/ \mathrm{ml}$. Radiolabelled $\mathrm{CM}$ and cell lysates were prepared as described above for unlabelled samples, and analysed by SDS/polyacrylamide-gel electrophoresis and autoradiography.

\section{SDS/polyacrylamide-gel electrophoresis and autoradiography}

SDS/polyacrylamide slab-gel electrophoresis of ${ }^{35} \mathrm{~S}$ labelled proteins was performed under reducing conditions according to the method of Laemmli (1970), with resolving gels of $10 \%(\mathrm{w} / \mathrm{v})$ acrylamide and stacking gels of $4 \%(\mathrm{w} / \mathrm{v})$ acrylamide. Protein $M_{\mathrm{r}}$ standards were used for calibration of the gel. For autoradiography, the gel was treated with an autoradiofluorography enhancer (En ${ }^{3} \mathrm{Hance}$ ) according to the manufacturers' instructions, dried and placed on X-ray film (Kodak AXR) for the appropriate time at $-90^{\circ} \mathrm{C}$.

\section{Assays}

Human endothelial cells in culture produce an excess of PAI-1 activity which impedes a straightforward functional assay of t-PA activity in CM and cell extracts (Kooistra et al., 1986). t-PA production was therefore investigated by measuring t-PA antigen or by performing fibrin autography. t-PA antigen in CM was assessed by an enzyme immunoassay, as described by Rijken et al. (1984), or by a commercially available t-PA e.l.i.s.a. kit from Biopool. Both assays gave comparable results. In fibrin autography, an observation by Granelli-Piperno \& Reich (1978) was exploited: complexes between plasminogen activator and its inhibitor show, after SDS/ 
Table 1. Effect of cyclic AMP and butyrate on the production of t-PA and PAI-1 by endothelial cells

Human umbilical vein endothelial cells were incubated for $24 \mathrm{~h}$ with various compounds at the indicated concentration, and the CM were analysed for t-PA antigen and PAI-1 activity as described in the Materials and methods section. Results are expressed as percentage values of controls and are means \pm S.D. for the number of independent experiments in parentheses, with incubations in duplicate.

\begin{tabular}{lccc}
\hline & & \multicolumn{2}{c}{ Production (\% of control) } \\
\cline { 3 - 3 } Addition & Concn. & t-PA antigen & PAI-1 activity \\
\hline None & & $100 \%$ & $100 \%$ \\
Dibutyryl cyclic AMP & $0.5 \mathrm{mM}$ & $68.3 \pm 7.1 \%(4)$ & $98.1 \pm 6.8 \%(4)$ \\
& $1.0 \mathrm{mM}$ & $86.5 \pm 35.6 \%(4)$ & $87.8 \pm 5.4 \%(4)$ \\
& $2.0 \mathrm{mM}$ & $104.9 \pm 34.1 \%(4)$ & $92.8 \pm 18.8 \%(4)$ \\
8-Bromo cyclic AMP & $5.0 \mathrm{mM}$ & $183.7 \pm 21.2 \%(4)$ & $94.2 \pm 15.5 \%(4)$ \\
Ethanol & $5.0 \mathrm{mM}$ & $96.4 \pm 7.4 \%(3)$ & $76.9 \pm 9.9 \%(3)$ \\
Forskolin $10 \mu \mathrm{M}+$ ethanol & $0.1 \%(\mathrm{v} / \mathrm{v})$ & $94.3 \pm 19.8 \%(4)$ & $110.1 \pm 13.1 \%(4)$ \\
Butyrate & $0.1 \%(\mathrm{v} / \mathrm{v})$ & $79.2 \pm 12.6 \%(4)$ & $70.6 \pm 12.5 \%(4)$ \\
& $10 \mathrm{mM}$ & $666.4 \pm 81.4 \%(4)$ & $51.4 \pm 9.8 \%(4)$ \\
\hline
\end{tabular}

polyacrylamide-gel electrophoresis and removal of SDS with Triton X-100, activity on fibrin underlays.

(Production of) PAI-1 activity in CM was quantified by titration of samples with increasing amounts of t-PA, followed by spectrophotometric measurement of the residual t-PA activity, as reported by Verheijen et al. (1984). Latent PAI-1 activity was assessed by SDS/ polyacrylamide-gel electrophoresis, followed by reverse fibrin autography as described by Erickson et al. (1984) and Sprengers et al. (1984). Regions of the SDS/ polyacrylamide-gel containing inhibitor are indicated by the formation of opaque, lysis-resistant areas in the indicator-film.

\section{Preparation of poly(A) ${ }^{+}$RNA and Northern blot hybridization}

The isolation of poly(A) ${ }^{+}$RNA from endothelial-cell cultures was essentially as described by Medcalf $e t$ al. (1986), with the exception that cells were lysed directly in the plates without prior trypsinization. $\operatorname{Poly}(\mathrm{A})^{+}$RNA was fractionated by electrophoresis in a $1 \%(w / v)$ agarose gel under denaturing conditions using $1 \mathrm{M}$ formaldehyde (Maniatis et al., 1982), and blotted to GeneScreen according to the manufacturers' instructions. The filters were pre-hybridized under standard conditions as described by Maniatis et al. (1982), i.e. in the presence of $0.1 \%(\mathrm{w} / \mathrm{v}) \mathrm{SDS}, 100 \mu \mathrm{g}$ of heat-denatured salmon sperm DNA $/ \mathrm{ml}, 50 \%(\mathrm{v} / \mathrm{v})$ deionized formamide, $5 \times \mathrm{SSC} / 5 \times$ Denhardt's [Ficoll $(1 \mu \mathrm{g} / \mathrm{ml})$, polyvinylpyrrolidone $(1 \mu \mathrm{g} / \mathrm{ml})$, bovine serum albumin $(1 \mu \mathrm{g} / \mathrm{ml})]$. Hybridization was performed overnight at $42^{\circ} \mathrm{C}$ in the same solution containing $10-50 \mathrm{ng}$ of a ${ }^{32} \mathrm{P}$-labelled $\mathrm{probe} / \mathrm{ml}$. The t-PA riboprobe was derived from a nearly full-length t-PA cDNA insert of pPA11 4B (Fisher et al., 1985) which was subcloned in pGEM-1 (Melton et al., 1984); a t-PA riboprobe was then generated by T7polymerase transcription of the t-PA-pGEM template (specific activity approx. $10^{8}$ c.p.m./ $\mu \mathrm{g}$ of DNA). The PAI-1 probe was a partial (1400 bp) cDNA copy of the human PAI-1 gene (Van den Berg et al., 1987), and radiolabelled by 'nick' translation (Maniatis et al., 1982). The specific radioactivity of this ${ }^{32} \mathrm{P}$-labelled probe was approx. $10^{7}$ c.p.m. $/ \mu$ g of DNA. Filters were washed three times for $10 \mathrm{~min}$ at room temperature with
$2 \times$ SSC containing $0.1 \%(\mathrm{w} / \mathrm{v})$ SDS, and twice for $30 \mathrm{~min}$ at $40^{\circ} \mathrm{C}$ with $0.1 \times$ SSC containing $0.1 \%(\mathrm{w} / \mathrm{v})$ SDS. The filters were then exposed to Kodak XAR-5 $\mathrm{X}$-ray film for $16 \mathrm{~h}$ using an intensifying screen. The relative intensity of the bands present on the autoradiogram was read on a scanning densitometer.

\section{RESULTS}

\section{Effect of cyclic AMP and butyrate on the production of} t-PA and PAI-1

In view of the widespread involvement of cyclic AMP in cellular regulatory processes, we investigated the relationship, if any, between this compound and the synthesis of t-PA and its inhibitor, PAI-1, in cultured human endothelial cells. As seen in Table 1, 24 h incubation of endothelial cells with dibutyryl cyclic AMP at concentrations of $0.5-5.0 \mathrm{~mm}$ resulted in a slight decrease in PAI-1 activity, a decrease in t-PA antigen production at the lower test concentrations, but a significant, about 2-fold, increase in t-PA antigen production at $5 \mathrm{~mm}$-dibutyryl cyclic AMP. To further investigate whether an enhancement of the intracellular cyclic AMP pool would give identical results, 8-bromo cyclic AMP and forskolin, an activator of adenylate cyclase, were tested. 8-Bromo cyclic AMP $(5 \mathrm{~mm})$ did not change t-PA antigen production significantly, but lowered the accumulation of PAI-1 activity. Forskolin $(10 \mu \mathrm{M})$ reduced both t-PA antigen production and PAI1 activity. During incubation with dibutyryl cyclic AMP, butyrate residues are slowly liberated. Therefore an amount of free butyrate equivalent to $5 \mathrm{~mm}$-dibutyryl cyclic AMP was added to endothelial cell cultures. The addition of $10 \mathrm{~mm}$-butyrate resulted in a very strong increase in t-PA production, with a concomitant decrease in PAI-1 activity. The stimulating effect of $5 \mathrm{~mm}$ dibutyryl cyclic AMP on t-PA production is thus probably the result of liberated butyrate.

\section{Dose-dependency and time-course of the stimulatory effect of butyrate on t-PA synthesis in relation to the production of PAI-1}

As seen in Fig. 1, increasing amounts of butyrate caused an increasingly stimulatory effect on t-PA 


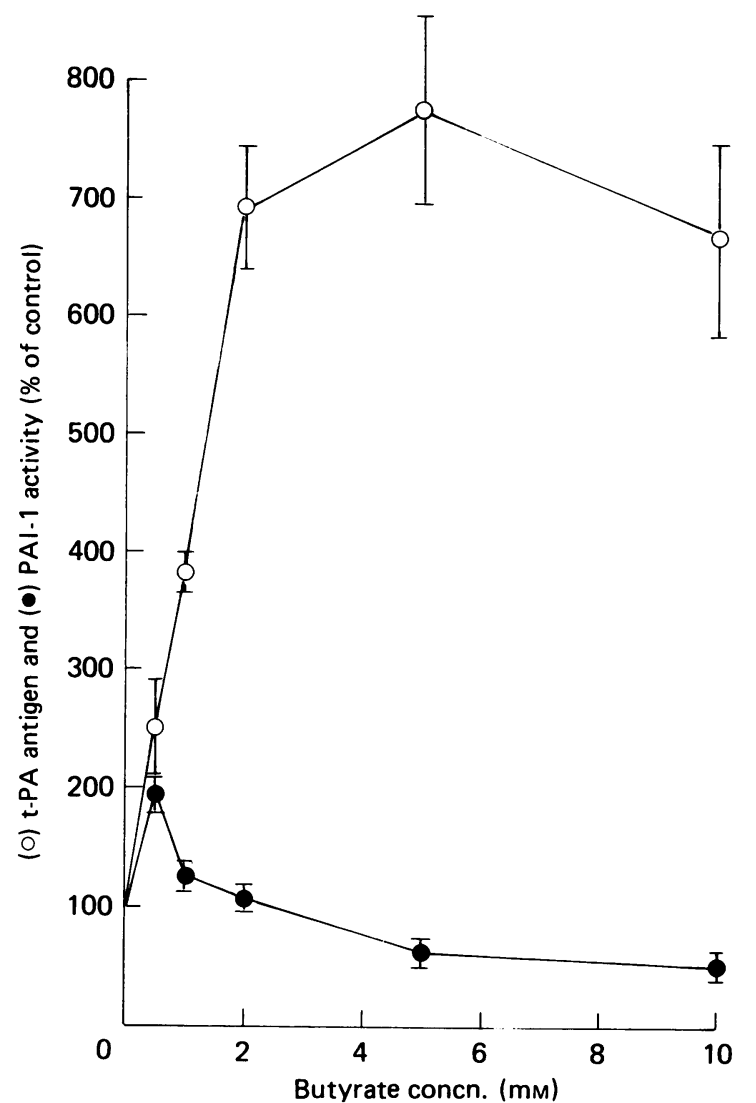

Fig. 1. Dose-dependency of the effect of butyrate on t-PA antigen and PAI-1 activity production in cultured endothelial cells

Human umbilical vein endothelial cells were incubated for $24 \mathrm{~h}$ with differing concentrations of butyrate, and the CM were analysed for t-PA antigen and PAI-1 activity as described in the Materials and methods section. Results are expressed as percentage values of controls and are means \pm S.D. for four independent experiments, with incubations in duplicate. $O$, t-PA antigen;, PAI-1 activity.

production, reaching a plateau at $5 \mathrm{~mm}$ of butyrate or more. In the series of experiments shown in Fig. 1, maximally a 7- to 8-fold increase in t-PA antigen is reached after $24 \mathrm{~h}$ of incubation. The relative elevation of t-PA production at an optimal concentration of $5 \mathrm{~mm}$ butyrate varied among different endothelial cell cultures from 6- to 25-fold in $24 \mathrm{~h} \mathrm{CM}$. The stimulatory effect of butyrate was observed with endothelial cells from both venous and arterial origin. Analysis by fibrin autography confirmed the dose-dependent increase in lytic activity of CM from butyrate-treated cells. As illustrated in Fig. 2, $24 \mathrm{~h} \mathrm{CM}$ from control as well as butyrate-treated cells show two lysis bands using this technique, with an apparent molecular mass around 100000 . The intensity of both lytic zones increases with increasing test concentrations of butyrate. Both 100000 lytic zones are related to t-PA activity, as demonstrated by inhibition by anti-(t-PA) IgG, and are probably the result of the activity of the complex between t-PA and PAI-1, as addition of purified t-PA to t-PA-depleted CM resulted in similar lysis bands around 100000 after SDS/ polyacrylamide-gel electrophoresis and fibrin autography

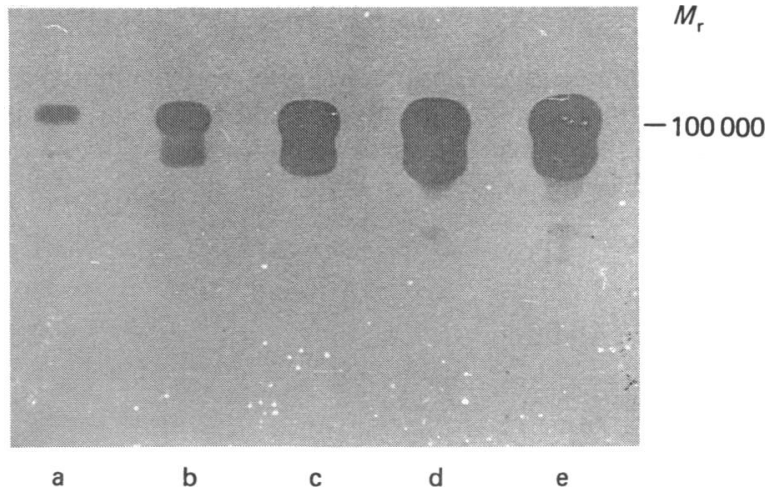

Fig. 2. Effect of butyrate on fibrinolytic activity in endothelial cell conditioned medium

Human umbilical vein endothelial cells were incubated for $24 \mathrm{~h}$ with differing concentrations of butyrate, and the plasminogen activator activity in the $\mathrm{CM}$ was visualized by fibrin autography after SDS/polyacrylamide-gel electrophoresis. Lane a, control; lane b, $0.5 \mathrm{~mm}$-butyrate; lane c, 1.0 mm-butyrate; lane d, $2.0 \mathrm{~mm}$-butyrate; lane e, 5.0 mM-butyrate.

(results not shown). Examination of the cell extracts from control and $24 \mathrm{~h}$ butyrate-treated cells by fibrin autography showed a picture comparable with that obtained with the corresponding CM: a $100000-M_{\mathrm{r}}$ lytic zone which was much more concentrated in treated cells than in control cells (results not shown).

Increasing amounts of butyrate resulted in a relatively moderate enhancement of PAI-1 activity at the lower test concentrations, but caused a fall in inhibitor activity at the higher test concentrations (Fig. 1; see also Table 2). This fall in PAI-1 activity can at least partly be explained by complexing of active PAI-1 molecules with the elevated levels of t-PA in the CM. In addition to active PAI-1, there is a second, inactive or latent form of PAI-1 which has no inhibitory activity until it has been treated with a protein denaturant (Sprengers et al., 1984, 1985; Hekman \& Loskutoff, 1985; Levin, 1986). Analysis of $24 \mathrm{~h} \mathrm{CM}$ from control and butyrate-treated cells by reverse fibrin autography showed no difference in the amount of inactive inhibitor in both preparations (Fig. 3).

Fig. 4 shows a typical experiment in which the timecourse of the butyrate effect is illustrated. In control CM, the amount of t-PA produced by the cells increases linearly with time. When $5 \mathrm{~mm}$-butyrate is added to the medium, an accelerated accumulation of t-PA antigen in $\mathrm{CM}$ is observed after a lag period of about 6-8 h. A similar lag period was observed when CM were analysed by fibrin autography (results not shown).

\section{$\left[{ }^{35}\right.$ S]Methionine studies}

Protein synthesis by endothelial cell cultures was determined by incubating cells for $8 \mathrm{~h}$ or $24 \mathrm{~h}$ in complete incubation medium [including $10 \%(\mathrm{v} / \mathrm{v})$ human serum], and containing $\left[{ }^{35}\right.$ S]methionine, followed by measuring the incorporation of the radiolabel into trichloroacetic acid-precipitable protein in cells and CM. There was little effect of butyrate on total protein synthesis (values in the range of $95 \%-115 \%$ of the control). To explore the possibility that butyrate changes the pattern of 


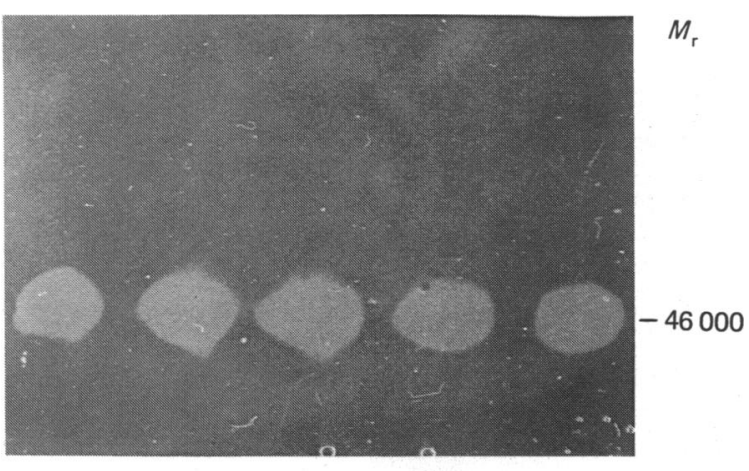

a $b$

d

Fig. 3. Effect of butyrate on PAI-1 production in cultured endothelial cells

Human umbilical vein endothelial cells were incubated for $24 \mathrm{~h}$ with differing concentrations of butyrate, and the CM were analysed for the presence of (latent) PAI-1 by reverse fibrin autography. Lane a, control; lane b, $0.5 \mathrm{~mm}$ butyrate; lane c, $1.0 \mathrm{~mm}$-butyrate ; lane d, $2.0 \mathrm{~mm}$-butyrate; lane e, $5.0 \mathrm{~mm}$-butyrate.

proteins synthesized by endothelial cells, cells were preincubated for $24 \mathrm{~h}$ with or without butyrate, followed by an incubation of $2 \mathrm{~h}$ in serum- and methionine-free medium, containing $0.03 \%(\mathrm{v} / \mathrm{w})$ human serum albumin and ${ }^{35}$ S]methionine. CM and cell extracts were then analysed by SDS/polyacrylamide slab-gel electrophoresis and autoradiography. As seen in Fig. 5, the protein profiles observed with cells pre-incubated with butyrate were rather similar to those observed with control cells, suggesting that the action of butyrate on t-PA synthesis is a rather specific effect. In accordance with this conclusion is the absence of a marked effect on the production of PAI-1. This is illustrated in Fig. 5 by the same intensity of the $46000-M_{\mathrm{r}}$ PAI-1 band in control and butyrate-containing media, and is in agreement with the data on PAI-1 given in Fig. 3. Two clear differences induced by butyrate-treatment of the cells were the appearance of an approx. $60000-M_{\mathrm{r}}$ protein and the disappearance of a slightly larger protein in the CM. The identity of these proteins has not yet been determined.

\section{Structural specificity studies}

Fig. 6 illustrates the structural specificity of butyrate analogues ( $5 \mathrm{mM}$ ) for the increased production of t-PA in cultured human endothelial cells. Among the straightchain carbonic acids, the $\mathrm{C}_{4}$ compound butyrate was the most effective. Propionate $\left(C_{3}\right)$ and valerate $\left(C_{5}\right)$ also markedly stimulated t-PA synthesis, but acetate $\left(\mathrm{C}_{2}\right)$ and hexanoate $\left(\mathrm{C}_{6}\right)$ were only marginally effective. Isobutyrate, the branched-chain analogue of butyrate, and crotonate, which contains a double bond between the second and third carbon atom in comparison with butyrate, were not, or only weakly, stimulatory, as were 2-oxobutyrate, GABA (4-aminobutyrate) and succinate. The other compounds tested, butanol, $\gamma$-butyrolactone (intramolecular lactone), 2-hydroxybutyrate, 3-hydroxybutyrate and 4-hydroxybutyrate even suppressed t-PA production. For comparison, Fig. 6 also shows that all of the butyrate analogues have no or only a small effect on the accumulation of PAI-1 activity in endothelial CM. The results presented in Table 2 further illustrate the

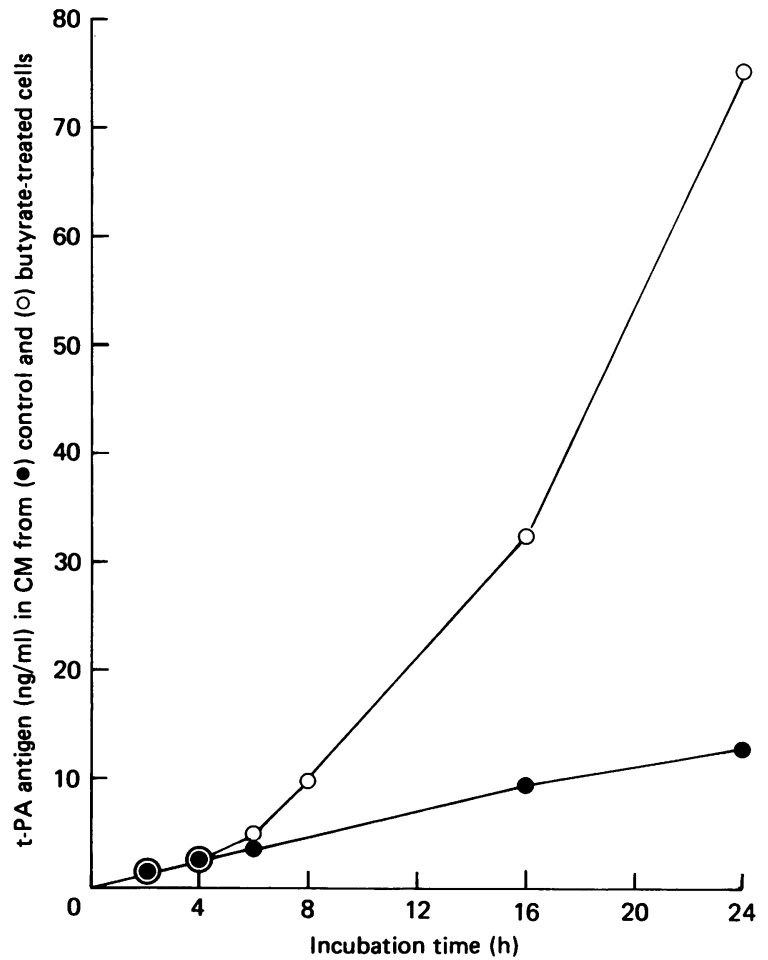

Fig. 4. Time-course of butyrate effect on $t-P A$ antigen production

Human umbilical vein endothelial cells were incubated for various times up to $24 \mathrm{~h}$ with $(O)$ or without (O) $5 \mathrm{~mm}$ of butyrate, and the CM were analysed for t-PA antigen.

stringent molecular requirements for optimal stimulation of t-PA production in endothelial cells: esterification of the carboxy group or replacement of a $\mathrm{C}$ atom by an $\mathrm{O}$ atom diminish considerably the potency of the butyrate molecule.

\section{Butyrate-mediated increase of t-PA mRNA}

The increased production of t-PA with butyrate could result from a stimulated mRNA accumulation or from a selectively increased rate of translation. To clarify this, the effect of butyrate on the concentration of t-PA mRNA was assessed by Northern blot hybridization. Fig. 7 shows that both control and butyrate-stimulated endothelial cells contain a single t-PA mRNA species, with a length of approx. 2500 nucleotides. Poly(A) ${ }^{+}$ RNA from butyrate-stimulated ( $5 \mathrm{mM}, 24 \mathrm{~h}$ ) endothelial cells contained approx. 30 times as much t-PA mRNA as poly(A) ${ }^{+}$RNA from control cells. These results support the hypothesis that butyrate stimulates t-PA production in endothelial cells through its effect on t-PA mRNA levels. For comparison, the two poly(A) ${ }^{+}$RNA preparations were also analysed for PAI-1 mRNA. Two transcripts were found, with a length of approx. 2300 and 3000 nucleotides, respectively (Fig. 7). In contrast to t-PA mRNA, the total amount of PAI-1 mRNA did not differ markedly in the two poly(A) ${ }^{+}$RNA preparations.

\section{DISCUSSION}

Human endothelial cell cultures constitute a useful model for the evaluation of the role of the endothelium in the modulation of fibrinolysis and for the investigation 
Cells

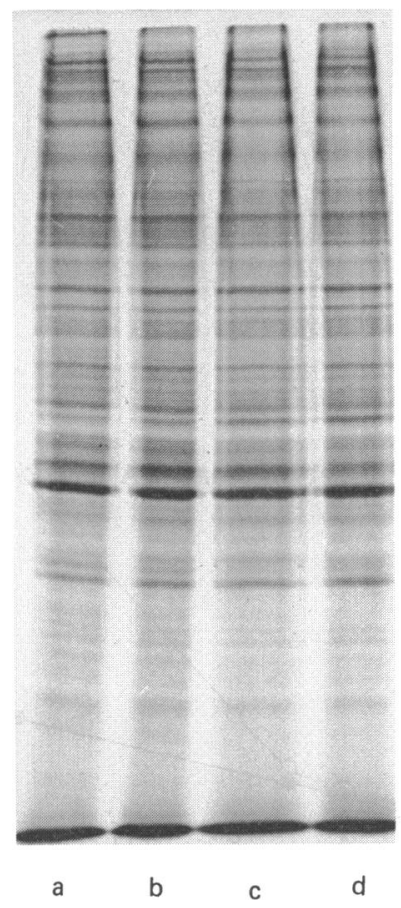

$\mathrm{CM}$

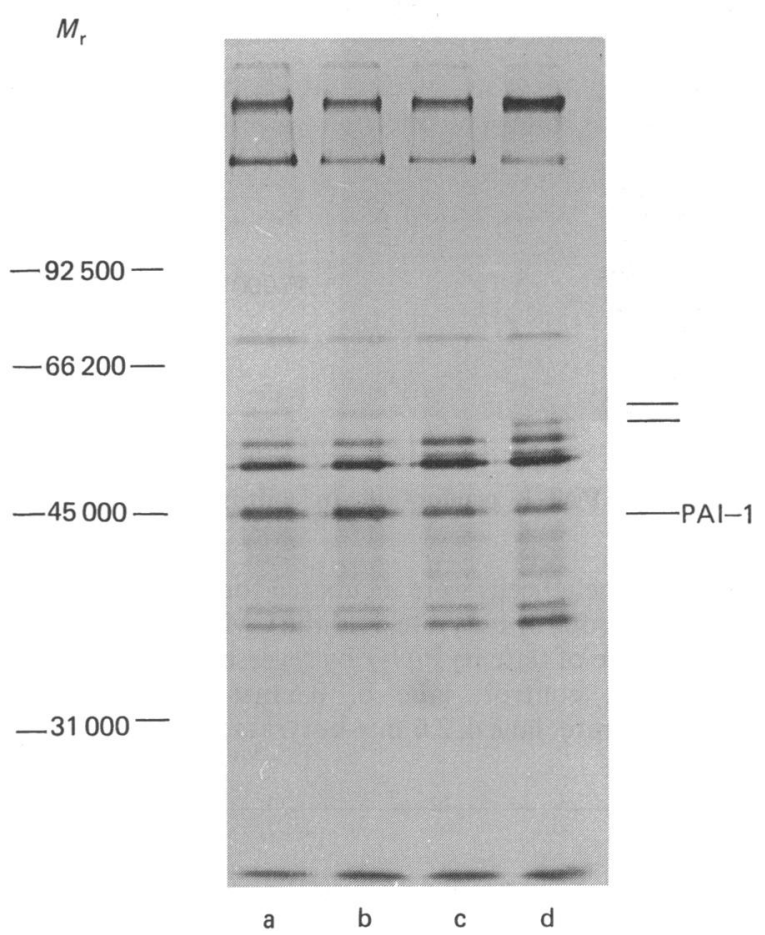

Fig. 5. SDS/polyacrylamide-gel electrophoresis and autoradiography of metabolically radiolabelled proteins synthesized by endothelial cells in culture

Human umbilical artery endothelial cells were incubated for $24 \mathrm{~h}$ with differing concentrations of butyrate before labelling for $2 \mathrm{~h}$ with $\left[{ }^{35} \mathrm{~S}\right]$ methionine. Cell lysates (cells) and proteins secreted into the conditioned medium (CM) were processed for electrophoresis and fluorography as described in the Materials and methods section. $9.8 \times 10^{4}$ c.p.m. (cell lysates) or $9 \times 10^{3}$ c.p.m. $(\mathrm{CM})$ of ${ }^{35} \mathrm{~S}$-labelled protein (as determined by trichloroacetic acid-precipitable protein) were applied to each lane, and the fluorogram was exposed for $20 \mathrm{~h}$ (cell lysates) or 4 days (CM). Molecular mass standards are indicated, and migration of PAI-1 at $M_{\mathrm{r}}=46000$, as verified by specific immunoprecipitation, is marked. Lane a, control; lane b, 0.5 mM-butyrate; lane c, 2.0 mM-butyrate; lane d, 5.0 mM-butyrate.

of the effects of pharmacologic agents on the production of t-PA and PAI-1. We have used this model system for screening compounds that can enhance t-PA synthesis without a concomitant increase in the production of its inhibitor, PAI-1. In a previous communication (Kooistra et al., 1985) we reported that dibutyryl cyclic AMP had a positive effect on the synthesis of t-PA. The present study shows that this stimulatory effect of dibutyryl cyclic AMP is the result of liberated free butyrate rather than the result of enhanced intracellular cyclic AMP levels (Table 1). There are a vast number of reports in the literature about the effects of butyrate on the regulation of gene expression in a number of cell types (for a review see Kruh, 1982). To our knowledge, the effect of butyrate on cultured human endothelial cells has not been reported before.

The induction of t-PA by butyrate in endothelial cells is dependent on time, with a lag period of $6-8 \mathrm{~h}$, and on butyrate concentration, reaching a plateau at $5 \mathrm{~mm}$ or more (Figs. 1 and 4). The increases in t-PA antigen in the CM were accompanied by elevations in fibrinolytic activity as analysed by fibrin autography (Fig. 2). The effect of butyrate on PAI-1 release has also been studied. This inhibitor is present in two forms, an active form which binds to t-PA, and an inactive or latent form which has no inhibitory activity, but can be converted to its active counterpart by denaturing agents like SDS, guanidine $\mathrm{HCl}$, or urea (Sprengers et al., 1984, 1985;
Hekman \& Loskutoff, 1985; Levin, 1986). The two forms of PAI-1 also differ in their thermal stability: the activity of the active form is labile to incubation at $37^{\circ} \mathrm{C}$ and declines with a half-life of about $2 \mathrm{~h}$. The latent form is stable to incubation at $37^{\circ} \mathrm{C}$ and accumulates linearly in time in the CM. The inactive form is found in excess of the active inhibitor in $\mathrm{CM}$ of human endothelial cells: in $24 \mathrm{~h} \mathrm{CM}$ up to an 80-fold excess of the inactive form over the active form has been reported (Hekman \& Loskutoff, 1985; Kooistra et al., 1986; Levin et al., 1986). No significant change in inactive-inhibitor production was observed following butyrate addition (Fig. 3), implying that the overall rate of synthesis of PAI-1 is relatively constant (see also Fig. 5). In agreement with this conclusion is the observation that mRNA levels of PAI-1 did not differ markedly between control and butyrate-treated cells (Fig. 7). On the other hand, the level of active inhibitor in $24 \mathrm{~h} \mathrm{CM}$ was elevated up to two times with cells incubated with low butyrate concentrations, and was diminished to about $50 \%$ at the high butyrate concentrations. This variation in amount of active inhibitor may be the result of changes in the relative rate of production of active inhibitor versus inactive inhibitor or changes in the rate of conversion of active to inactive inhibitor. The decrease in inhibitor activity at the higher butyrate concentrations can at least partly be accounted for by complexing of active inhibitor with elevated levels of t-PA. 


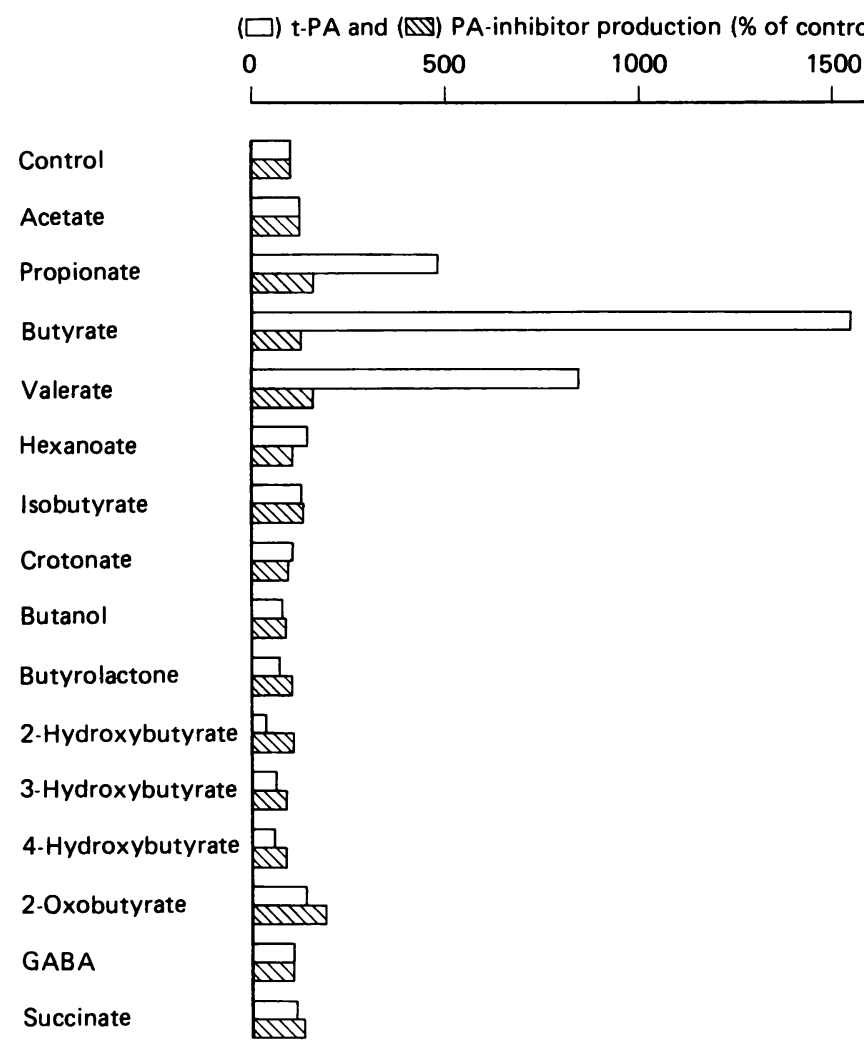

Fig. 6. Structural specificity of butyrate effect

Endothelial cells were incubated with various butyrate analogues ( $5 \mathrm{mM}, 24 \mathrm{~h}$ ), and the CM were analysed for t-PA antigen and PAI-1 activity as described in the Materials and methods section. Abbreviation: GABA, 4-aminobutyrate.

Butyrate is a natural lipid component. It is formed in significant amounts during fatty acid synthesis in a number of mammalian tissues (Abdinejad et al., 1981). It is interesting that such a common, simple, $\mathrm{C}_{4}$ fatty acid has such a strong biological activity (see also Kruh, 1982). It is very likely that butyrate itself is active rather than a metabolic product since other even-chain fatty

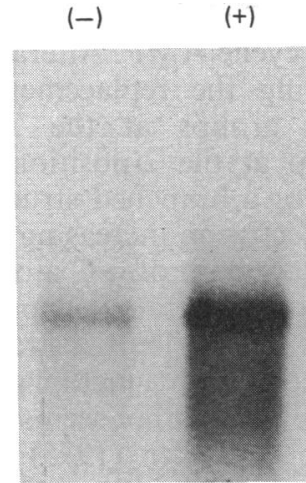

(a)
Fig. 7. Effect of butyrate on t-PA and PAI-1 mRNA levels in cultured endothelial cells

Human umbilical vein endothelial cells were incubated for $24 \mathrm{~h}$ in the absence $(-)$ or presence $(+)$ of 5 mM-butyrate. Poly(A) ${ }^{+}$RNA was extracted, and $4 \mu \mathrm{g}$ of RNA from each culture was subjected to electrophoresis on an agarose/ formaldehyde gel and transferred to GeneScreen. The RNA blot was hybridized with a ${ }^{32} \mathrm{P}$-labelled t-PA or PAI1 probe, and then exposed to Kodak XAR-5 X-ray film using an intensifying screen. The intensity of the bands present on the autoradiogram were assessed by scanning densitometry. (a) Hybridization with a t-PA probe. (b) Hybridization with a PAI-1 probe.

acids are much less effective, and are metabolized through the same pathway. In our study of the relationship between structure and stimulatory activity we found that butyrate was by far the most effective inducer of t-PA synthesis (Fig. 6). Shortening or lengthening the carbon chain by one carbon atom decreased the stimulatory effect after $24 \mathrm{~h}$ of incubation by $50-70 \%$. Further changes in the length of the carbon chain almost completely suppressed the stimulatory activity. Similarly, the introduction of a terminal amino or alcohol group, the replacement of the terminal methyl group by a carboxy group, or the formation of an intramolecular lactone abolished the inducing activity. Esterification of the carboxy group diminished but did not abolish the

\section{Table 2. Effect of ethyl butyrate and methoxyacetate on the production of t-PA and PAI-1 by endothelial cells}

Endothelial cells were incubated for $24 \mathrm{~h}$ with various concentrations of ethyl butyrate, methoxyacetate, or, for comparison, butyrate, and the CM were analysed for t-PA antigen and PAI-1 activity as described in the Materials and methods section. Results are mean values of incubations in duplicate with percentage values relative to control in parentheses. The ranges of values were $<15 \%$ of the means.

\begin{tabular}{lccc}
\hline Addition & $\begin{array}{c}\text { Concen- } \\
\text { tration } \\
(\mathrm{mM})\end{array}$ & $\begin{array}{c}\text { t-PA antigen } \\
(\mathrm{ng} / \mathrm{ml})\end{array}$ & $\begin{array}{c}\text { PAI-1 } \\
\text { activity } \\
\text { (i.u./ml) }\end{array}$ \\
\hline None & - & $5.6(100 \%)$ & $39(100 \%)$ \\
Butyrate & 0.5 & $20.9(373 \%)$ & $55(141 \%)$ \\
& 1.0 & $46.5(830 \%)$ & $60(154 \%)$ \\
Ethyl butyrate & 5.0 & $78.2(1396 \%)$ & $22(56 \%)$ \\
& 0.5 & $11.8(211 \%)$ & $41(105 \%)$ \\
Methoxyacetate & 1.0 & $17.1(305 \%)$ & $34(87 \%)$ \\
& 5.0 & $25.7(459 \%)$ & $34(87 \%)$ \\
& 0.5 & $5.5(98 \%)$ & $47(121 \%)$ \\
& 1.0 & $9.4(168 \%)$ & $43(110 \%)$ \\
& 5.0 & $19.5(348 \%)$ & $46(118 \%)$ \\
& 10.0 & $26.8(479 \%)$ & $50(128 \%)$
\end{tabular}


effect (Table 2), possibly due to hydrolysis of the ester bond as is the case in dibutyryl cyclic AMP. Alterations of the aliphatic chain, including the replacement of hydrogen atoms by hydroxy groups at the 2- or 3 -position or by an oxo group at the 2-position, the introduction of a double bond or a branched structure, rendered these compounds ineffective in increasing t-PA synthesis (Fig. 6). Only the replacement of a $\mathrm{C}$ atom by an $\mathrm{O}$ atom, as is the case in methoxyacetate, left part of the stimulatory activity intact (Table 2). Thus, a straightchain $\mathrm{C}_{4}$ monocarboxylate structure with a methyl group at one end and a carboxy moiety at the other seems to be required for induction. Leder \& Leder (1975) have reported a similar structural specificity for inducing haemoglobin synthesis in mouse leukaemia cells. Ghosh et al. (1977) also found that induction of human choriogonadotropin in HeLa cell cultures by aliphatic monocarboxylates exhibits similar structural specificities. Recently, Tanaka \& Nishida (1985) observed such a structural specificity for the induction of fibronectin synthesis in rabbit cornea.

We have demonstrated that the butyrate-induced increase in t-PA production can be explained by increased t-PA-mRNA levels in endothelial cells (Fig. 7). Since butyrate is known to enhance (and/or induce) transcription of chromatin (Kruh, 1982), it is likely that the increase in t-PA-mRNA levels we observed was the result of increased t-PA-mRNA production, rather than stabilization of previously synthesized mRNAs or changes in RNA processing. Such transcriptional effects of butyrate have been attributed to its ability to induce hyperacetylation of the histone proteins by inhibition of the histone deacetylases (Riggs et al., 1977). Increase in histone acetylation would be expected to expose more segments of chromatin making them more amenable to expression. As shown in Fig. 5, only few changes in the pattern of the major endothelial cell proteins were detectable after metabolic labelling with $\left.{ }^{35} \mathrm{~S}\right]$ methionine and analysis by SDS/polyacrylamide-gel electrophoresis. Similarly, no marked effect on PAI-1 synthesis was seen. No attempt was made to determine the mechanism whereby butyrate relatively selectively stimulates t-PA production in endothelial cells. Future experiments should reveal the effect of butyrate on overall transcription, processing, mRNA stability, translation, and protein stability in endothelial cells.

In summary, we have shown that butyrate is a very potent inducer of t-PA synthesis in cultured human endothelial cells. This finding demonstrates that under basal culture conditions the pro-fibrinolytic potential of endothelial cells is only partially exploited. The effect of butyrate can thus serve as a positive control in future experiments directed at promoting the pro-fibrinolytic state of the endothelial cell.

We thank Mr. A.C. W. de Bart for expert technical assistance. D. C. Rijken is an 'Established Investigator' of the Dutch Heart Foundation. This work was supported by the 'Praeventiefonds', project 28-813.

\section{REFERENCES}

Abdinejad, A., Fisher, A. \& Kumar, S. (1981) Arch. Biochem. Biophys. 208, 135-145
Emeis, J. J., Brommer, E. J. P., Kluft, C. \& Brakman, P. (1985) in Recent Advances in Blood Coagulation (Poller, L., ed.), vol. 4, pp. 11-33, Churchill-Livingstone, Edinburgh, London, Melbourne and New York

Erickson, L. A., Lawrence, D. A. \& Loskutoff, D. J. (1984) Anal. Biochem. 137, 454-463

Erickson, L. A., Hekman, C. M. \& Loskutoff, D. J. (1985) Proc. Natl. Acad. Sci. U.S.A. 82, 8710-8714

Fisher, R., Waller, E. K., Grossi, G., Thompson, D., Tizard, R. \& Schleuning, W.-D. (1985) J. Biol. Chem. 260, $11223-11230$

Gaffney, P. J. \& Curtis, A. D. (1985) Thromb. Haemostasis 53, 134-136

Ghosh, N. K., Rukenstein, A. \& Cox, R. P. (1977) Biochem. J. 166, 265-274

Granelli-Piperno, A. \& Reich, E. (1978) J. Exp. Med. 148, 223-234

Hekman, C. M. \& Loskutoff, D. J. (1985) J. Biol. Chem. 260, 11581-11587

Jaffe, E. A., Nachmann, R. L., Becker, C. G. \& Minick, C. R. (1973) J. Clin. Invest. 52, 2745-2756

Kluft, C., Van Wezel, A. L., Van der Velden, C. A. M., Emeis, J. J., Verheijen, J. H. \& Wijngaards, G. (1983) in Advances in Biotechnological Processes (Mizrahi, A. \& Van Wezel, A. L., eds.), vol. 2, pp. 97-110, Alan R. Liss, New York

Kooistra, T., Van den Berg, A. P., Emeis, J. J. \& Princen, J. M. G. (1985) Thromb. Haemostasis 54, 171 (abstr.)

Kooistra, T., Sprengers, E. D. \& Van Hinsbergh, V. W. M. (1986) Biochem. J. 239, 497-503

Kruh, J. (1982) Mol. Cell. Biochem. 42, 65-82

Kruithof, E. K. O., Tran-Thang, C., Ransijn, A. \& Bachmann, F. (1984) Blood 64, 907-913

Laemmli, U.K. (1970) Nature (London) 227, 680-685

Leder, A. \& Leder, P. (1975) Cell 5, 319-322

Levin, E. G. (1986) Blood 67, 1309-1313

Maciag, T., Cerundolo, J., Ilsley, S., Kelley, P. R. \& Forand, R. (1979) Proc. Natl. Acad. Sci. U.S.A. 76, 5674-5678

Maniatis, T., Fritsch, E. F. \& Sambrook, J. (1982) Molecular Cloning: A Laboratory Manual, Cold Spring Harbor Laboratory, Cold Spring Harbor

Medcalf, R. L., Richards, R. I., Crawford, R. J. \& Hamilton, J. A. (1986) EMBO J. 5, 2217-2222

Melton, D. A., Krieg, P. A., Rebagliati, M. R., Maniatis, T., Zinn, K. \& Green, M. R. (1984) Nucleic Acids Res. 12, 7035-7056

Riggs, M. G., Whittaker, R. G., Neumann, J. R. \& Ingram, V. W. (1977) Nature (London) 268, 462-464

Rijken, D. C., Wijngaards, G. \& Welbergen, J. (1980) Thromb. Res. 18, 815-830

Rijken, D. C., Van Hinsbergh, V. W. M. \& Sens, E. H. S. (1984) Thromb. Res. 33, 145-153

Sprengers, E. D. (1986) Thromb. Haemostasis 55, 74-77

Sprengers, E. D., Verheijen, J. H., Van Hinsbergh, V. W. M. \& Emeis, J. J. (1984) Biochim. Biophys. Acta 801, 163-170

Sprengers, E. D., Princen, H. M. G., Kooistra, T. \& Van Hinsbergh, V. W. M. (1985) J. Lab. Clin. Med. 105, 751-758

Tanaka, H. \& Nishida, T. (1985) J. Cell. Physiol. 123, 191-196

Todd, A. S. (1959) J. Pathol. Bacteriol. 78, 281-283

Van den Berg, E. A., Sprengers, E., Jaye, M., Burgess, W. \& Van Hinsbergh, V. W. M. (1987) Thromb. Haemostasis 58, 15 (abstr.)

Van Hinsbergh, V. W. M., Havekes, L., Emeis, J. J., Van Corven, E. \& Scheffer, M. (1983) Arteriosclerosis 3, 547-559

Verheijen, J. H., Chang, G. T. G. \& Kluft, C. (1984) Thromb. Haemostasis 51, 392-395

Wiman, B., Chmielewska, I. \& Rånby, M. (1984) J. Biol. Chem. 259, 3644-3647

Received 12 May 1987/20 July 1987; accepted 23 July 1987 